\title{
AB ELEKTRİK İÇ PAZARINA UYUM SÜRECINDE ÜYE ÜLKELERDEN BAZILARINA TANINAN AYRICALIKLAR VE TÜRKIYE'NIN KONUMU
}

\author{
Bülent ORAL" \\ Nazif Hülâgü SOHTAOĞLU** \\ Irfan GÜNEY***
}

\section{Özet:}

Avrupa Parlamentosu ve Avrupa Birliği Bakanlar Konseyi'nde kabul edilen 19 Aralık 1996 tarihli 96/92/EC Elektrik Direktifi ve 16 Haziran 2003 tarihli 2003/54/EC Yeni Elektrik Direktifi, rekabete açık bir iç elektrik piyasasının oluşumunu hedeflemektedir. Üye ve aday ülkelerin ulusal elektrik enerjisi sektörlerinde direktifleri tam olarak uygulaması, hedeflenen tek elektrik pazarının gerçekleşebilmesi için önemlidir.Bu çalışmada, AB elektrik direktiflerinin üye ülkelerdeki uygulanmalart sürecinde yaşanan farklıllklar üzerinde durulmuştur. Bu kapsamda AB tarafindan özellikle Yunanistan ve İlanda'ya verilen ayricalıkların nedenleri sorgulanmıştır. Bununla beraber yasal alt yapının oluşturulması ve uygulanmasinda yaşadıkları zorluklar açısından Fransa ve Belçika gibi ülkelerin durumu incelenmistir. Böylece $A B$ direktiflerinde istenen rekabetçi bir yapının ve yapılandırmanın, gerçekte üye ülke elektrik enerji sektörlerinde ne kadar uygulandığı irdelenmiştir. Çalışmanın son aşamasında, AB aday ülkesi Türkiye'nin elektrik enerjisi sektörü, üye ülkelerdeki uygulamaların ışı̆̆ altında karşılaştırmalı olarak ortaya konmuştur.

Anahtar Kelimeler: Elektrik piyasalar, yeniden yapılanma, rekabet.

\section{Abstract:}

The Electricity Directive 96/92/EC and newer Electricity Directive 2003/54/EC that were approved by the EU Parliament and EU Council has targeted an internal electricity market open to competition. Implementation of these directives by both the Member States and the candidate countries is vitally important for achieving this end. This paper examines the differences between the implementation of EU electricity direvtives in various Member States. The reasons for the privilages of Ireland and Greece are questioned. Besides this, difficulties of forming the necessary infrastructure in some

\footnotetext{
*Yrd.Doç.Dr., Marmara Üniversitesi

** Doç. Dr., Istanbul Teknik Üniversitesi

${ }^{* * *}$ Prof. Dr., Marmara Üniversitesi
} 
countries -like France and Belgium-are also examined. These examples allowed to evaluate the success of Member State implementation of EU electricity directives.In the final part of this paper, the Turkish electricity market is evaluated with respect to EU electricity directives and Member States implementation.

Keywords: Electricity markets, restructuring, competition.

\section{Giriş}

96/92/EC ve 2003/54/EC Elektrik Direktifleri, AB içerisinde rekabete açık bir iç elektrik piyasasının oluşumunu hedeflemektedir. Avrupa Birliği Komisyonu tarafından hazırlanan çeşitli çalışmalarda ifade edilen ve Floransa Forumlarında görüşülen bölgesel elektrik piyasalarının oluşumunun temelinde de iç elektrik piyasasına geçiş bulunmaktadır.

Hedeflenen tek elektrik pazanına geçiş; Birlik ülkelerinin enerji sektörlerini yeniden yapılandırmasını, rekabete açmasını ve piyasaların işleyişinde birlikteliğe yönelik çalışmaların öncelikle ulusal pazarlarda uygulamaya konulmasını gerektirmektedir.

AB direktiflerine uyumun sağlandığı ulusal pazarların kurulması ile bölgesel pazarlara geçiş olacak ve hedef olan tek elektrik pazar daha kolay sağlanacaktır. Şekil 1'de hedeflenen tek elektrik piyasası yol haritası sunulmuştur. Bu kapsamda Avrupa Komisyonu'nun Mart 2005 strateji raporunda önerilen bölgesel elektrik piyasaları aşağıda verilmiştir (Eurelectric, 2005):

- İskandinav ülkeleri (Danimarka, İsveç, Norveç ve Finlandiya),

- İngiltere ve İrlanda,

- Batı Avrupa (Fransa, Almanya, Hollanda, Belçika, Lüksemburg, Avusturya ve İsviçre),

- İberya yarımadası (İspanya ve Portekiz),

- Doğu Avrupa (Slovenya, Macaristan, Slovakya, Çek Cumhuriyeti ve Polonya),

- Italya,

- Güney-Doğu Avrupa (Atina forumunda bulunan ülkeler),

- Baltık ülkeleri (Estonya, Letonya ve Litvanya) 


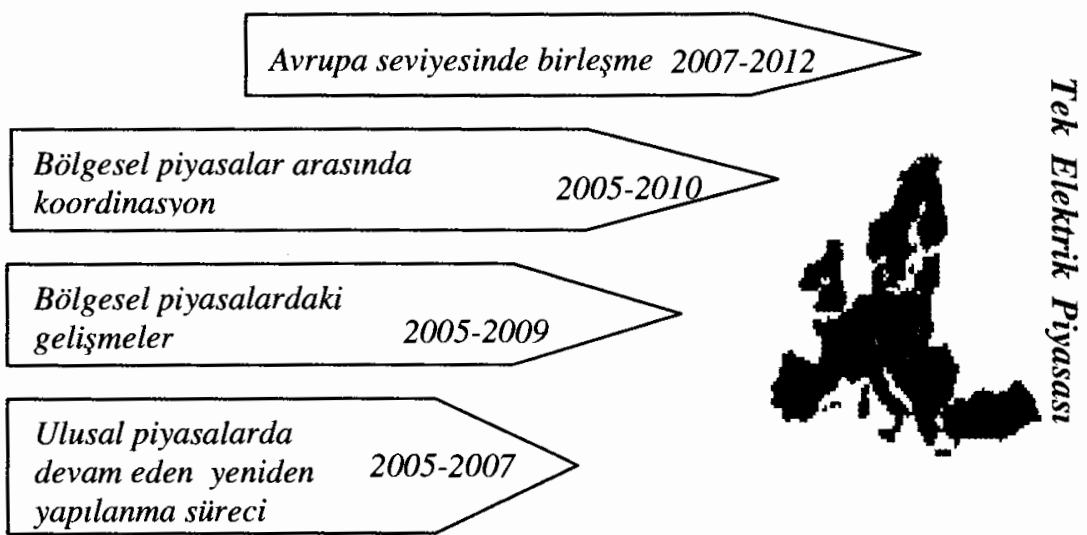

Şekil 1. Tek Avrupa elektrik piyasasının yol haritası (Eurelectric, 2005)

\section{96/92/EC Elektrik Direktifi}

Avrupa Birliği'ne üye ülkelerin enerji sektörlerindeki uyumunun sağlanması amacıyla, Avrupa Parlamentosu ve Avrupa Birliği Bakanlar Konseyi tarafından 19 Aralık 1996 tarihinde elektrik sektöründeki ortak pazar kurallarını düzenleyen bir direktif yürürlüğe konulmuştur (96/92/EC).

96/92/EC direktifi ile elektrik piyasasının serbestleştirilerek rekabete açılması hedeflenmiştir. Bu kapsamda üye ülkelerin kamu yararı göz önünde bulundurması istenmiş, ayrıca elektrik sektöründe faaliyet gösteren şirketler üzerinde arz güvenliği, fiyat ayarlamaları, elektriğin kalitesi ve çevre korumasına iliş̧in çeşitli sorumluluklar ifade edilmiştir. Ayrıca yükümlülüklerin açık bir şekilde tanımlanması ile birlikte şeffaflık ve eşitlik ölçülerine göre düzenlenmesi gerektiği özellikle vurgulanmıştır (Akkaya, 2000: 157-168).

Yirmidokuz maddeden oluşan 96/92/EC Elektrik Direktifi'nin maddelerinde, sektörün yeniden organizasyonu üzerinde durularak; üretim, iletim, dağıtım sektörlerinin birbirinden ayrıştırılması ve işleyişi ile üretim ve tedarik için rekabetin oluşumu sunulmuştur. Bununla beraber sisteme erişim hakkında, giriş ve tarife şartları ile piyasada oluşması istenen şeffaf yapı üye ülkeler için ifade edilmiştir. Aynca arz güvenliği ile yenilenebilir ve yerli kaynakların kullanımı hususlarında kamu hizmeti zorunlulukları da açıklanmıştır (European Parliament, 1996).

Piyasanın rekabete açılımı konusunda büyük tüketiciler ve dağıtım şirketleri hedeflenmiş, Şubat 1999 için \%26 (40 GWh/y1l), Şubat 2000 tarihi 
için \% $28 \quad(20 \mathrm{GWh} / \mathrm{yl})$ ve Şubat 2003 tarihi içinde \%33 $(9 \mathrm{GWh} / \mathrm{yl})$ minimum hedefleri belirlenmiştir (Thomas, 2005).

$\mathrm{Bu}$ hedeflerin sağlanması ise, büyük tüketicilere serbest olarak kendi tedarikçilerini seçme hakkı verilmesi ile mümkün olabilir.

\section{2003/54/EC Elektrik Direktifi}

23-24 Mart 2000 tarihinde gerçekleşen Avrupa Konseyi Lizbon toplantısında, elektrik iç piyasasının tamamlanması, sektördeki kurumların serbestleşmesi çalışmalarının hızlanması ve perakende satış rekabetine dayalı işleyişin tam olarak sağlanması için bazı görüşler sunulmuştur. Mart 2001'de AB Komisyonu tarafından serbestleşme hareketini hızlandıracak bu girişimlere yeni öneriler getirilmiştir. Bu bağlamda 96/92/EC direktifi için önerilen değişikler, taslak üzerinde ifade edilmiştir. Taslak çalışmada, 2005 yılı için belirtilen piyasanın rekabete $\% 100$ açılımı görüşünün yanında, şebekeye erişimdeki 96/92/EC direktifinde izin verilen müzakereye tabi erişim ile tek satıcılı yapı seçeneklerinin kaldırılması önerilmiştir. 7 Haziran 2002 tarihinde $\mathrm{AB}$ Komisyonu tarafından hazırlanan değişiklik önerileri Parlamento ve Konsey'e sunulmuștur (Cameron, 2002).

5 Kasım 2002 tarihli AB'ye üye ülkelerin enerji bakanlarının katıldığ Konsey toplantısında yapılan bu değişiklik önerileri tartışılmış ve politik anlaşmaya ulaşılmıştır. AB'nin ortak karar işleyişi çerçevesinde, Avrupa Konseyi'nin elektrik iç pazarının oluşması ve sınır ötesi elektrik ticareti hakkındaki tüzük değişikliklerine ilişkin ortak tutumu (Common Position) 3 Şubat 2003 tarihli AB resmi gazetesinde (Official Journal of the European Union) yayınlanmıştır.

"Yeni Elektrik Direktifi" ve "Sınır Ötesi Elektrik Ticareti Düzenlemesi" AB Parlamentosu'nda ve Avrupa Konseyi'nde 16 Haziran 2003'te benimsenmiştir (2003/54/EC). "Yeni Elektrik Direktifi", Mart 2001 tarihli AB Komisyonu değişiklik düzeltmesinde ifade edilen piyasanın rekabete açılma tarihlerini değiştirmiş ve 1 Temmuz 2004 tarihine kadar konut müşterileri hariç tüm tüketicilere serbest tüketici niteliği kazandırılmasını hedeflemiştir. Ayrica 2003/54/EC direktifinde, 1 Temmuz 2007 tarihinde üye ülkelerdeki tüm tüketicilerin istedikleri tedarikçileri seçme hakkına kavuşacakları belirtilmiştir (European Commission, 2003).

Yeni Elektrik Direktifi ve Sınır Ötesi Elektrik Ticareti Düzenlenmesi'nin uygulanması, düzenleyici yapıda bulunan farklı sorumluluklardaki değişik kurulların birbiri arasındaki yakın eşgüdümünün sağlanması ile olabilir. Eşgüdümün sağlanmasında öne çıkan kurumlar; Avrupa Komisyonu, üye 
devletlerin hükümetleri, ulusal düzenleyiciler, iletim sistem operatörleri ile elektrik enerjisi piyasasının ortaklarıdır.

2003/54/EC direktifinin uygulanmasına geçilecek tarih olan 2004 yılı ortasına kadar, elektrik enerjisi sektörü için yasal dayanağın 96/92/EC direktifi olmasına karar verilmiştir.

\section{Elektrik Direktiflerinin Üye Ülkelerde Yerine Getirilmesi}

96/92/EC Elektrik Direktifi, yayınlandıktan iki ay sonra yürürlüğe konulmuştur. Üye ülkelerin farklı alt yapı ve ekonomik durumlarını göz önünde bulundurularak, 19 Şubat 1999 tarihine kadar, AB üyesi onbeş ülkenin onikisi tarafindan kendi mevzuatlarına dahil etmeleri hedeflenmiştir. Ayrıcalık olarak direktifte, Belçika ve İrlanda için 19 Şubat 2000, Yunanistan için ise 19 Şubat 2001 tarihi belirlenmiştir (Schwarz, 2000:4-7).

İlgili tarihler, direktifin getirdiği zorunlulukların minimum uygulanmaya konulması istenilen tarihlerdir.

Belçika, Yunanistan ve İrlanda'nn direktifte böyle bir ayricalık almasında elektrik piyasa kapasitelerinin küçüklüğgi bir etken olmakla beraber, Yunanistan ve İrlanda'nın $\mathrm{AB}$ ana yapısından izole olması da iki ülke için gözden uzak tutulmaması gereken bir başka noktadır .

Fransa, gerekli yasal mevzuatı ifade edilen tarihten bir yıl sonra çıkarmıştır. $\mathrm{Bu}$ durum $\mathrm{AB}$ Komisyonu tarafından işleyişin ihlal edildiğinin bildirilmesine neden olmuştur. 10 Şubat 2000 tarihinde yasalaşan 2000-108 numaralı kanunun (Loi de la modernisation et du dévelopement du service public de l'électricité), Haziran 2000 tarihinde AB Komisyonu tarafından kapsamının bir daha gözden geçirilmesi istenmiş ve Komisyon Fransa hükümetine bir uyarı mektubu göndermiştir. Bu kanun 2003-8 numaralı 3 Ocak 2003 tarihli yasayla revize edilmiştir (Freshfields Bruckhaus Deringer, 2003).

Belçika'da elektrik direktifinin yerine getirilmesindeki başarısızlığın koşulları farklıdır. Eylül 2001 tarihine kadar bir sistem operatörünün atanması başarılamamıştır. Bu nedenle ülkedeki büyük sanayi tüketicileri, AB Komisyonu'na şikayette bulunmuşlardır. AB Komisyonu, 96/92/EC direktifine göre iletim sistem operatörü oluşturmaması nedeniyle Şubat 2001 'de Belçika hükümetine durumu bildiren bir yazı göndermiş ve devamında durumun Eylül 2001'de ECJ'e (Europe Court of Justice Avrupa Adalet Divanı) havale edilmesine karar verilmiştir (Cameron, 2002). 
96/92/EC Elektrik Direktifinin uygulamaya konulması sonrasında elektrik üretiminde ondört üye ülkeden (Lüksemburg hariç) altısında (Belçika, Fransa, Yunanistan, İtalya, Portekiz ve İrlanda) piyasa işleyişi olarak, tekelci yapının devam ettiği görülmektedir. Birçok ülke, direktif sonrası perakende satış rekabetine odaklanmıştır.

Piyasanın tam olarak rekabetçi yapı altında işlemesinde, üretimde gerçek rekabet olmasi büyük önem taşımaktadır. Sadece perakende satışta rekabetin yaşanması sistemin işleyişi açısından çok önemli bir anlam taşımamaktadır.

Sisteme üçüncü şahıslarnn girişi için 96/92/EC direktifi üç seçenek sunmuştur:

- Tek alıc1l sistem (Single Buyer),

- Müzakere yoluyla sisteme giriş (negotiated Third Party Access -nTPA)

- Önceden düzenleyici tarafından açıklanan yani düzenlenen şartlar ile sisteme giriş (regulated Third Party Access - rTPA).

Üye ülkelerden sadece Almanya müzakere yoluyla sistem girişini seçmiştir. Bu üç yöntemden tek alıcılı sistem 2003/54/EC direktifinde kaldırılmış ve düzenlenen şartlar ile sisteme giriş yeni direktifte uygulanması istenen yapı olarak önerilmiștir (Thomas, 2005).

Tablo 1'de AB Üyesi ülkelerin elektrik direktifleri uygulamaları verilmiştir (European Commission, 2004; European Commission, 2005). Bu tablo ile üye ülkelerin elektrik enerji piyasalarını rekabete açma oranları, değerleri ile birlikte sunulmuştur. Büyük piyasalarda gerçekleşen rekabete açılma oranları önem taşımaktadır. Rekabete açılma oranlarıyla Almanya, İngiltere, İtalya, İsveç ve Norveç öne çıkmaktadır.

1 Mayıs 2004 sonrası üye olan ülkelerin pazar paylarnndaki küçüklük ve direktifler tarafından konulan şartların sağlanması konusundaki alınması gereken yol, dikkat çekici şekilde Tablo 1.'de görünmektedir. Ülkelerin pazar paylarındaki üretim şirketleri incelendiğinde ise, rekabetin tam olarak sağlanamadığı bazı üye ülkeler gerçeği ile karşılaşılmaktadır. Örneğin Fransa, Belçika, İrlanda, Lüksemburg, Portekiz ve Yunanistan eski üye olmalarına karşın Edf, Electrabel, ESB, EDP ve PPC üretim şirketleri ile piyasalarındaki tekelci şirket yapilannın sürdürmektedirler (S.Thomas, 2005). Mayıs 2004 sonrası üye olan ülkelerden Kıbrıs Rum Kesimi ve Malta'da, Kıta Avrupası'ndan olan izolasyonu ve küçük pazarlarıyla direktif şartlarını yerine getirme konusunda sıkıntılar gözlenmektedir. 
Tablo 1. Elektrik Direktifinin üye ülkeler ve Türkiye'de yerine getirilmesi

\begin{tabular}{|c|c|c|c|c|c|c|}
\hline Ülkeler & $\begin{array}{c}\text { Piyasa } \\
\text { açılımı } \\
(\%)\end{array}$ & $\begin{array}{c}\text { İletim } \\
\text { sistemindeki } \\
\text { ayrışma }\end{array}$ & $\begin{array}{l}\text { Dağıtım } \\
\text { sistemindeki } \\
\text { ayrışma }\end{array}$ & $\begin{array}{c}\text { Piyasaya } \\
\text { giriş için } \\
\text { dengeleme } \\
\text { koşullarının } \\
\text { uygunluğu }\end{array}$ & $\begin{array}{l}\text { Rekabete } \\
\text { açılan } \\
\text { piyasanın } \\
\text { değeri } \\
\text { (TWh) }\end{array}$ & $\begin{array}{l}\text { En büyük } \\
\text { üç } \\
\text { üreticinin } \\
\text { Payı }(\%)\end{array}$ \\
\hline Almanya & 100 & Yasal & Hesap & Uygun değil & 490 & 72 \\
\hline Avusturya & 100 & Yasal & Hesap & Uygun & 55 & 54 \\
\hline Belçika & 80 & Yasal & Yasal & Uygun değil & 60 & 95 \\
\hline Danimarka & 100 & Yasal & Yasal & Uygun & 33 & 40 \\
\hline Finlandiya & 100 & Mülkiyet & Hesap & Uygun & 77 & 40 \\
\hline Fransa & 37 & Yasal & Hesap & Orta & 140 & 96 \\
\hline Hollanda & 63 & Mülkiyet & Yasal & Uygun & 64 & 69 \\
\hline İngiltere & 100 & Mülkiyet & Yasal & Uygun & 335 & 39 \\
\hline İlanda & 56 & Yasal & Yönetim & Orta & 12 & 93 \\
\hline İspanya & 100 & Mülkiyet & Yasal & Uygun & 205 & 69 \\
\hline İsveç & 100 & Mülkiyet & Yasal & Uygun & 135 & 40 \\
\hline İtalya & 66 & Mülkiyet & Yasal & Orta & 182 & 65 \\
\hline Norveç & 100 & Mülkiyet & Hesap & Uygun & 115 & 40 \\
\hline Lüksemburg & 57 & Yasal & Hesap & Uygun değil & 3 & 88 \\
\hline Portekiz & 45 & Mülkiyet & Yönetim & Orta & 18 & 76 \\
\hline Yunanistan & 34 & Yasal & Hesap & Uygun değil & 15 & 97 \\
\hline Çek Cum. & 30 & Yasal & Hesap & Uygun değil & 15 & 76 \\
\hline Estonya & 10 & Yasal & Hesap & Uygun değil & $<1$ & 95 \\
\hline Letonya & 11 & Yasal & Yasal & - & $<1$ & 95 \\
\hline Litvanya & 17 & Yasal & Yasal & Orta & $<1$ & 92 \\
\hline Macaristan & 30 & Hesap & Hesap & Orta & 9 & 66 \\
\hline Polonya & 51 & Yasal & Hesap & Orta & 48 & 45 \\
\hline Slovakya & 41 & Yasal & Yasal & Orta & 4 & 86 \\
\hline Slovenya & 64 & Yasal & Hesap & Uygun değil & 6 & 87 \\
\hline KibrisRum. & 0 & - & - & - & 1 & 100 \\
\hline Malta & 0 & - & - & - & - & 100 \\
\hline Türkiye & 23 & Yasal & Hesap & Uygun değil & 24 & 62 \\
\hline
\end{tabular}

2003/54/EC direktifi sonrasında gerekli yasal alt yapının sağlanması için 1 Temmuz 2004 tarihi belirlenmiştir. Fakat üye ülkelerin çoğu direktifin yerine getirilmesinde ve gerekli yasal alt yapının oluşturulmasında belirlenen tarihi geciktirmişlerdir. Ekim 2004 tarihinde AB Komisyonu 
onsekiz üye ülkeye gerekli yasal alt yapı oluşturmamaları nedeniyle uyarı mektubu gönderilmiştir. Mart 2005 tarihinde listedeki ülke sayısı ona düşmüş ve son olarak dört ülke, Yunanistan, Lüksemburg, Portekiz ve İspanya 2003/54/EC direkifinin gereği olan yasal alt yapıyı sağlamadıkları için Komisyon tarafından ECJ'ye havale edilmiştir (Thomas, 2005; Cameron, 2002).

\section{Türkiye'nin Konumu}

1996 tarihli 96/92/EC direktifi sonrası, Enerji Tabii Kaynaklar Bakanlığı tarafından enerji sektörünün yeniden yapılanması amacıyla 1997 yılında çalışmalar başlatılmıştır. Kasım 2000 tarihinde AB'ye Katılım Ortaklığı Belgesi'nin sunulmasiyla beraber Aralı 2000 tarihli IMF niyet mektubunda ve Dünya Bankası "Ekonomik Reform Kredisi” Anlaşması'nda yapılan taahhütlerin sonucunda Bakanlar Kurulu 14 Ocak 2001 tarihinde Elektrik Piyasası Kanunu tasarısını TBMM'ye sevk etmiştir. 26 Ocak'ta Plan ve Bütçe Komisyonu'nda görüşülerek son şeklini alan tasarı, 20 Şubat 2001'de TBMM Genel Kurulu'nda kabul edilmiş ve 3 Mart 2001 tarihinde yürürlüğe girmiştir.

4628 sayılı Elektrik Piyasası Kanunu (EPK) sonrasında, sektör yeniden yapılandırılmış, dikey yapı içerisinde ayrışma sağlanmıştır. Üretim ve iletim faaliyetlerinde dikey ayrışma sonucunda, üretimde Elektrik Üretim Anonim Şirketi (EÜAŞ), elektrik enerjisi iletim faaliyetlerini yürütmek üzere, kamu mülkiyetindeki tüm iletim tesislerinin sahibi ve sistem operatörü olan Türkiye Elektrik İletim Anonim Şirketi (TEİAŞ) ile ticaret, taahhüt işlerini yürütmek ve toptan satış faaliyetinde bulunmak üzere Türkiye Elektrik Ticaret ve Taahhüt Anonim Şirketi (TETAŞ) oluşturulmuştur.

Ayrıca dağıtım boyutunda, dağıtım hatları ve perakende satış olmak üzere dikey ayrışma hedeflenmiştir. Yasa sonrası yeniden yapılanan elektrik sektörünün denetlemesi ve düzenlemesi amacı ile, bağımsız kurum olan, Enerji Piyasası Düzenleme Kurumu (EPDK) kurulmuştur.

Dağıtım ile perakende satış şirketlerinin dikey ayrışımı ile ilişkili olarak birçok $\mathrm{AB}$ ülkesi yasal veya hesap ayrışımı yollarından birini seçmektedir. Türkiye'de dağıtım ile perakende satış şirketlerinin dikey ayrışımı için hesap ayrıştırma çalışmaları sürmektedir.

Elektrik Piyasa Kanunu'nun yürürlüğe girdiği 2001 yılı itibarı ile ülkede dağıtım faaliyetinde bulunan kurumlar; bir kamu kurumu olan TEDAŞ, bu kuruma bağlı yedi ortaklık, Ayrıcalıklı Şirketler ÇEAŞ ve KEPEZ A.Ş ile Görev Şirketleri Kayseri Civarı Elektrik T.A.Ş. ve Aktaş’tır. Geçen zaman içerisinde bu kurumlardan Aktaş mahkeme kararı ile bu hakkını yeniden 
TEDAŞ'a bırakmıştır. Ayrıca ÇEAŞ ve KEPEZ'e de EPDK kararı ile devlet tarafından el konulmuştur. Kayseri bölgesinde elektriğin dağıtımı ve perakende satışını yürütmekte olan Kayseri ve Civarı Elektrik T.A.Ş. de hesaplarının aynışırılması çalışmalarını sürdürmektedir. EPDK tarafından dağıtım ve perakende satış faaliyetinde bulunan TEDAŞ ile bağlı ortaklıkları Karaelmas E.D.A.Ş, Trakya E.D.A.S , Başkent E.D.A.S, Boğaziçi E.D.A.Ş, Sakarya E.D.A.Ş, Körfez E.D.A.Ş ve Meram E.D.A.Ş’e 13.3.2003 tarihinden itibaren on y1llık "Dağıtım Lisansı" ve "Perakende Satış Lisansı" verilmiştir. Bununla beraber özelleştirme çalışmalarının başlangıcı olarak, ülke 21 ayrı dağıtım bölgesine ayrılmış ve buralarda yukarıdaki bağlı ortaklıklara ek olarak, yeni bağlı ortaklıklar oluşturulmuş̧ur (EPDK, 2006). Elektrik sektöründeki reforma ve özelleştirme stratejisine ilişkin strateji belgesi Yüksek Planlama Kurulu tarafından Mart 2004'de kabul edilmiştir. Bu kapsamda elektrik enerjisi sektöründe, özelleştirmenin de dahil olacağı sektörel reformu hedefleyen bir yol haritası ortaya konmuştur. Üretimle ilgili özelleştirmenin 2006 yılında başlatılması, dağıtımla ilgili özelleştirmenin ise 2006 yılı ortasında tamamlanması öngörülmektedir. Strateji belgesinde ifade edilen tarihlerin gerçekleşmediği görülmektedir.

Temmuz 2004 tarihi itibanyla, EPK'na getirilen ve özel dağıtım şirketlerinin, dağıtım ve üretim faaliyetlerinin hesapları birbirinden ayrı tutulmak kaydıyla, üretim tesisleri kurmalarını mümkün kılan değişiklik kabul edilmiştir. Bu durum üretim ve dağıtım şirketleri arasında sınırlı da olsa dikey birleşmeye izni vermektedir.

Ülkemizde tüm AB ülkelerinde olduğu gibi iletim ve dağıtım sistemine giriş düzenlenmiştir (Regulated Third Party Acces-“rTPA”). Bu, düzenleme kurumu tarafından belirlenen şartlar altında tüm tedarikçilerin serbest tüketiciye hat bedelini ödeyerek, enerji satışını yapabilmesi anlamına gelmektedir.

EPK sonrası oluşturulan EPDK tarafından Eylül 2002 tarihinde yayınlanan serbest tüketici yönetmeliğinde serbest tüketici, iletim sistemine doğrudan bağlı olanlar veya 3 Mart 2003 tarihinde bir önceki yıl toplam tüketimlerinin 9 milyon kWh'1 aşanlar olarak tanımlanmıştır. Serbest tüketiciler, tedarikçiler (perakende satış şirketleri, perakende satış lisansına sahip dağıtım şirketleri, toptan satış şirketleri veya üretim şirketleri) ile ikili anlaşmalar yapabilmektedirler. Bununla beraber serbest tüketicilerin çok zaman dilimli ölçüm yapabilen sayaçlara sahip olması zorunluluğu bulunmaktadır. 3.Mart.2003 tarihi itibarı ile 9 Milyon kWh sınırını geçen yaklaşık 500 civarı kuruluş olduğu ifade edilmektedir. Serbest tüketici 
limiti, EPDK'nun 25 Ocak 2006 tarihli 641 nolu kararı ile 6 milyon kWh düşürülmüşsür.

\section{Sonuç ve Değerlendirme}

“96/92/EC Elektrik Direktifi” ve "2003/54/EC Yeni Elektrik Direktifi”, $A B$ elektrik enerjisi sektöründe ortak pazar kurallarını düzenlemekte ve elektrik piyasasını serbestleştirerek rekabetçi bir yapıya kavuşmasını hedeflemektedir. Böylece $\mathrm{AB}$ direktiflerine uyumun sağlandığı ulusal piyasalardan bölgesel piyasalara geçiş olacak ve hedef olan tek elektrik piyasası gerçekleşecektir.

96/92/EC direktifi ortaya konulduğunda Avrupa Birliği onbeş ülkeden oluşmaktayken, 2003/54/EC direktifinin yürürlüğü girdiği Temmuz 2004 tarihinde Birlik, yirmibeş ülkeye ulaşmıştır. Bu kapsamda 2000 Lizbon stratejisinde ortaya konulan 2010 yılına kadar ekonomik olarak bir dünya gücü olma hedefi $\mathrm{AB}$ açısından önemlidir. Yayınlanan ilk direktifin üye ülkeler tarafından yerine getirilmesinde zorluklar gözlenmiştir.

Direktifin ortaya koyduğu serbestleşme ve rekabetçi yapının tam olarak sağlanmasında bazı ülkeler ulusal yapıda direnç ile karşılaşmışlardır. Belçika'da Electrabel'in tekel konumu ve piyasa tabanlı toptan pazarının olmaması, Fransa pazarında EdF'nin egemenliği ve direktife uyumda yasal zorlukların yaşanması gibi örnekler uygulamada oluşmuştur. Bununla beraber İrlanda ve Yunanistan'ın Birlik üyelerine olan izolasyonu ve aynı zamanda Lüksemburg ile birlikte elektrik enerjisi piyasalanının küçük olması nedeniyle bu ülkeler, takvimde hem ayrıcalıklar almışlar hem de piyasalarındaki tekelci yapıyı sürdürmüşlerdir. 2003/54/EC direktifinin yürürlüğï girmesi ile Mayıs 2004 sonrasında üye olan yeni ülkelerde de piyasa paylarındaki küçüklük (Estonya, Letonya, Litvanya gibi) ve Kıta Avrupası'ndan izole konum (Kıbrıs Rum Kesimi ve Malta) direktifin yerine getirilmesinde tıkanıklıklar oluşturmuştur.

Ulusal piyasalarda yaşanan zorluklardan biri ise, ulusal yapıdaki enerji şirketlerinin uluslararası pazarda girmek istedikleri ülkelerdeki piyasa payında yaşadıkları kısıtlamalarıdır. İtalya'da ENEL şirketinin özelleştirilmesi sırasında, EdF'nin satışa sunulan şirketi Belçika'da ortağ olduğu Suez enerji üzerinden hakim olma arzusu, İspanya'da ENDESA şirketinin Alman E.ON şirketi tarafından alınması isteği, İtalya ve İspanya hükümetleri tarafından engellenmiştir. 


\section{Kaynakça:}

Akkaya, İ., (2000). Türkiye'nin Avrupa Birliği'ne Tam Üyelik Adaylığının Tescil Edildiği Helsinki Zirvesi Sonrası Süreçte Türkiye-AB Enerji Mevzuatının Harmonizasyonu Faaliyetleri. Türkiye 8.Enerji Kongresi, Çağrılı Bildiriler Kitabı, 8-12 Mayıs, 157-168. Ankara: ODTÜ

"Annual Report on The Implementation of the Gas and Electricity Internal Market". (2005). Brussels: Commission of The European Communities.

Cameron, P.D., (2002). Competition in Energy Markets: Law and Regulation in The European Union. Oxford: Oxford University Press.

"Contribution to the Commission's Consultation on the Progress Report". (2005). Union of the Electricity Industry. Brusssels:EURELECTRIC.

"Directive Concerning: Common Rules for The Internal Market in Electricity". (1996). The European Parliament and The Council of The European Union. Brussels: European Parliament.

"Electricity Regulation 2003". (2003). International Law Firm. London: Freshfields Bruckhaus Deringer.

Enerji Piyasası Düzenleme Kurumu. Erişim: 01 Şubat 2006, www.epdk.gov.tr

"Third Benchmarking Report on the Implementation of the Internal Electricity and Gas Market". (2004). Brussels: Commission of The European Communities.

"Strategy Paper, Medium Term Vision for The Internal Electricity Market". (2003). European Commission Directorate-General for Energy and Transport. Brussels: European Commission.

Schwarz, J., Stachus, K., Knop,T., Zettler, K.R., (2000). Overview of The EU Electricity Directive. IEEE Power Engineering Review, April,4-7.

Thomas S., (2005). "The European Union Gas and Electricity Directives". Brussels: European Federation of Public Service Unions. 